\title{
Construction and Modeling of Multi-Circuit Multi-Voltage HVAC Transmission Lines
}

\author{
Agnieszka Dziendziel *,+(D), Henryk Kocot ${ }^{+}(\mathbb{D})$ and Paweł Kubek ${ }^{+}(\mathbb{D}$ \\ Department of Power System and Control, Faculty of Electrical Engineering, Silesian University of Technology, \\ 44-100 Gliwice, Poland; henryk.kocot@polsl.pl (H.K.); pawel.kubek@polsl.pl (P.K.) \\ * Correspondence: agnieszka.dziendziel@polsl.pl \\ † These authors contributed equally to this work.
}

Citation: Dziendziel, A.; Kocot, H.; Kubek, P. Construction and Modeling of Multi-Circuit Multi-Voltage HVAC Transmission Lines. Energies 2021, 14, 421. https://doi.org/10.3390/en14 020421

Received: 1 December 2020 Accepted: 12 January 2021 Published: 14 January 2021

Publisher's Note: MDPI stays neutral with regard to jurisdictional clai$\mathrm{ms}$ in published maps and institutional affiliations.

Copyright: (C) 2021 by the authors. Licensee MDPI, Basel, Switzerland. This article is an open access article distributed under the terms and conditions of the Creative Commons Attribution (CC BY) license (https:// creativecommons.org/licenses/by/ $4.0 /)$.

\begin{abstract}
A transmission network's main objective is to continuously supply electrical energy to consumers. This article presents an analysis of the use of multi-circuit, multi-voltage overhead lines as a compromise between ensuring the system's safe operation by increasing the transmission network capacity and managing the constraints related to its expansion. The considerations presented in this work include the construction of such lines, their operation, and modeling aspects. As part of the study, the potential for improving the environmental conditions around the lines is discussed in terms of the necessary area for their construction and the peak electromagnetic field strength in their vicinity. We also present a mechanical analysis of stress and sag coordination in the individual circuits of these lines. Then, we detail the method for determining the electrical parameters of multi-voltage lines' series impedances and capacitance. Specific attention is given to the possibility of zero-sequence voltage that occurs in the systems despite the symmetric supply and load of circuits-especially in the circuits with the lowest voltages-that result from the line's geometric asymmetry. We evaluate the impact of the line's geometric asymmetry on the power system's correct operation by determining the asymmetry factors. Finally, the accuracy of using a simplified symmetric model for lines with various geometric asymmetries is analyzed by studying the error of the short-circuit currents.
\end{abstract}

Keywords: overhead lines; optimal span length; electromagnetic field around transmission line; admittance model; symmetrical components; zero-sequence voltage; voltage quality; voltage unbalance; asymmetric line operation; asymmetry factors

\section{Introduction}

Ensuring the safe operation of power systems in the perspective of meeting the ever-increasing demands for power, while also accounting for changes taking place in the generation sector (e.g., new blocks with greater unit powers and areas with large surpluses of unstable production such as large networks of wind farms), requires enabling power flow through many independent electrical paths with sufficient density of the transmission network and a high capacity of the individual elements. The development of the transmission network is closely related to changes in the generation sector, along with the growing requirements for continuity and certainty of the energy supply. The fundamental element of the transmission network is lines, mainly overhead lines.

\subsection{The Scope of the Article}

This article focuses on multi-circuit, particularly multi-voltage, overhead lines. The issues we consider are of a general nature, and detailed examples are taken from the Polish power transmission system. This paper is divided into four main sections, which are preceded by a short introduction describing an overview of the solutions currently being used to ensure the power system's safe operation. Our discussion is from the perspective of the ever-growing demand for power and the characteristics of multi-circuit, multi-voltage transmission lines. Section 2 covers issues related to the requirements governing the 
construction of high voltage alternating current (HVAC) multi-circuit, multi-voltage lines. To this end, we analyze the optimal span length of this type of solution. In Section 3, the electromagnetic field strength in the vicinity of multi-circuit, multi-voltage transmission lines is evaluated. Then, in Section 4 the relevant elements related to the modeling of high voltage transmission lines in the power system structure are detailed, and the algorithm for calculating the electrical parameters of multi-circuit, multi-voltage line models is described. Specifically, we study the effect that geometric asymmetry has on the line and on the correct operation of the transmission network. In Section 5, we present our analysis of the influence that multi-circuit line asymmetry has on the system by determining the asymmetry factors in normal-state operation. These studies also include a series of short-circuit analyses that are used to determine the validity of using symmetric models to describe asymmetric multi-voltage lines, which we quantitatively assess via the accuracy of the short-circuit currents predicted by these models. Finally, in Section 6 the conclusions of our study are discussed in detail.

\subsection{Background of the Issue}

Many analyses and activities aim to increase the transmission capacity of existing transmission lines. These approaches include the modernization of existing overhead lines by increasing the operating voltage and implementing newer conductors, such as High Temperature Low Sag (HTLS) [1]. Another method that is growing in popularity analyzes current weather conditions to determine the actual permissible load capacity of transmission lines [2,3]. Here, the model estimates the current-carrying capacity and considers the risk of exceeding the conductors' permissible temperature, as doing so enables the full use of their transmission capacity. However, this solution requires continuous data acquisition from meteorological stations located in their region, which is a complex process.

The methods currently being used to increase the transmission capacity of the existing high voltage overhead lines are effective, but they may be insufficient in the long term. Therefore, there is a need to find additional solutions to ensure safe and efficient energy transmission to consumers. The obvious answer is to increase the transmission capacity of the network by building new lines; however, the construction of new overhead lines is associated with serious administrative, legal, and environmental constraints. Indeed, the preferred route of the planned overhead line is often impossible to implement due to local and regional spatial development plans of individual communes and detailed environmental and landscape conditions, including special protection objects.

The width of the route that the overhead line requires is a compromise between the technical aspects that guarantee the correct operation of the network, the field conditions, the dimensions of the transmission line supporting structure, and the safety of other devices and living organisms in its vicinity. Increasing the transmission voltages by simultaneously using the shared supporting structure allows for a significant reduction of the total width of the technological route. For example, considering only single-circuit lines carried on separate technological routes (arranged independently of each other), the transmission of $2000 \mathrm{MW}$ of power should use fifteen $110 \mathrm{kV}$ lines with a total route width of $450 \mathrm{~m}$. Instead of using fifteen $110 \mathrm{kV}$ lines, by increasing the rated voltage, four $220 \mathrm{kV}$ lines with a total route width of $200 \mathrm{~m}$ or a $400 \mathrm{kV}$ line with a route width of $70 \mathrm{~m}$ can be used [4]. Due to the large area needed for an overhead line, it is common practice to carry lines on parallel routes, often using the same route of another transmission line. For instance, carrying a $220 \mathrm{kV}$ and a $400 \mathrm{kV}$ double-circuit line on the same route allows the route width to be reduced by $25 \%$ compared to the route width needed to carry two separate single-circuit 400 and $220 \mathrm{kV}$ lines arranged side by side. If it is assumed that the ratio of the power transmitted on the line $P_{\mathrm{L}}$ to the route width $d$ for a $400 \mathrm{kV}$ and $220 \mathrm{kV}$ double-circuit line carried on independent routes is $100 \%$, then for the case described above (i.e., shared route), the transmitted power-to-width ratio $P_{\mathrm{L}} / d$ increases to $133 \%$. A further reduction of the route width allows for the use of a shared supporting structure. One four-circuit, doublevoltage line $2 \times 400+2 \times 220 \mathrm{kV}$ can transmit as much energy as one $400 \mathrm{kV}$ double-circuit 
line and one $220 \mathrm{kV}$ double-circuit line. However, the area occupied by the multi-circuit, multi-voltage structure is, in this case, approximately one half, with $P_{\mathrm{L}} / d=171 \%$. In this regard, using a multi-circuit, multi-voltage line is the most effective and deserves special attention when there is a need to install a transmission line in an area that is challenging to develop, e.g., mountainous, forest, urbanized areas. Additionally, the use of steel tubular pylons can also reduce both the dimensions of the overhead line supporting the structure to an even greater extent and accordingly, the width of the technological route. Such structures can be found, e.g., in the Netherlands (Table 1 no. 10) and in the United Kingdom, where $245 \mathrm{kV}$ and $400 \mathrm{kV}$ overhead lines are tested [5,6].

Table 1. Selected examples of multi-voltage transmission lines in the world [7].

\begin{tabular}{|c|c|c|c|c|c|}
\hline \multirow{2}{*}{ No. } & \multirow{2}{*}{ Country } & \multirow{2}{*}{ Number of Circuits } & \multirow{2}{*}{$\begin{array}{c}\text { Rated Voltage } \\
\mathbf{k V}\end{array}$} & \multicolumn{2}{|c|}{ Actual Length of the Multi-Circuit Section } \\
\hline & & & & km & $\%$ \\
\hline 1. & Denmark & 3 & $400+2 \times 150$ & 118 & $12.8 / 6.5$ \\
\hline 2. & Denmark & 2 & $400+150$ & 215 & 23.3/11.9 \\
\hline 3. & Denmark & 2 & $400+132$ & 7 & $0.8 / 0.7$ \\
\hline 4. & Germany & 3 & $380+2 \times 220$ & 38.5 & - \\
\hline 5. & Germany & 3 & $380+2 \times 150$ & 7.5 & - \\
\hline 6. & Germany & 3 & $380+2 \times 110$ & 135.7 & - \\
\hline 7. & Germany & 2 & $380+110$ & 4.6 & - \\
\hline 8. & Germany & 2 & $220+110$ & 1.7 & - \\
\hline 9. & Montenegro & 2 & $400+110$ & 40 & $14 / 5.8$ \\
\hline 10. & Netherlands & 4 & $2 \times 380+2 \times 170$ & - & - \\
\hline 11. & Lithuania & 2 & $330+110$ & 2.5 & $0.1 / *$ \\
\hline 12. & USA & 2 & $345+230$ & - & - \\
\hline 13. & USA & 2 & $230+115$ & - & - \\
\hline 14. & Switzerland & 3 & $2 \times 380+132$ & - & - \\
\hline 15. & Poland & 4 & $2 \times 400+220+110$ & 31.2 & $0.5 / 0.4 /-$ \\
\hline 16. & Poland & 3 & $2 \times 400+220$ & 4.8 & $* / *$ \\
\hline 17. & Poland & 3 & $400+2 \times 110$ & 6.5 & $0.1 /-$ \\
\hline 18. & Poland & 2 & $400+110$ & 43.0 & $0.7 /-$ \\
\hline 19. & Poland & 2 & $220+110$ & 7.5 & $0.1 /-$ \\
\hline $20 .^{\bullet}$ & Poland & 3 & $2 \times 400+220$ & $\sim 20$ & $0.3 / 0.3$ \\
\hline
\end{tabular}

Note: ${ }^{\bullet}=$ build scheduled for the years $2027-2030$ [8]; ${ }^{*}=$ less than $0.1 \%$.

The effectiveness of multi-circuit, multi-voltage transmission lines have been recognized in many countries around the world, as seen in Table 1 . The table also shows the percentage of the multi-voltage section's actual length being compared to the lines' total length for a given voltage and the corresponding country.

The Polish transmission network consists of 104 lines operating at a voltage of $400 \mathrm{kV}$ and with a total length of $7008 \mathrm{~km}, 164$ lines at $220 \mathrm{kV}$ with total length of $7570 \mathrm{~km}$, $33,357 \mathrm{~km}$ of overhead lines at $110 \mathrm{kV}$, a single line at $750 \mathrm{kV}$ with a total length of $114 \mathrm{~km}$, and a $450 \mathrm{kV}$ HVDC submarine connection with a total length of $254 \mathrm{~km}$ (including $127 \mathrm{~km}$ on the Polish side). The 400, 220, and $110 \mathrm{kV}$ networks operate in parallel as closed networks. In Poland, multi-circuit, multi-voltage lines do not constitute a significant share in the transmission and distribution networks; however, their multi-faceted advantages necessitate that further development of these networks is planned, as evidenced by the transmission network development plans for the coming years [8]. Indeed, the ratio of multi-circuit, multi-voltage transmission lines worldwide is much more significant; for instance, in Denmark, almost $40 \%$ of the $400 \mathrm{kV}$ transmission lines are multi-voltage construction (Table 1).

Design solutions for multi-circuit, multi-voltage lines are diverse. A more extensive overview of them can be found, among others, in [7]. In the proceeding parts of this article, for calculation purposes, two three-circuit lines (i.e., Lines 2 and 3, as in Table 1 no. 16 and no. 17, respectively) and a double-circuit line (Line 1 of classic construction) were 
used. Table 2 presents the coordinates of the phase and earth conductors' location $(x, y)$, calculated in relation to the axis of the tower $x$ and the earth's surface $y$.

Table 2. Location coordinates $x, y$ in meters of three considered multi-circuit transmission lines in Poland.

\begin{tabular}{|c|c|c|c|c|c|c|c|c|c|c|c|}
\hline & \multirow{3}{*}{$\begin{array}{l}\text { Circuit Number } \\
\text { (Rated Voltage) }\end{array}$} & \multicolumn{6}{|c|}{ Location Coordinates of Phase Conductors } & \multicolumn{4}{|c|}{$\begin{array}{l}\text { Location Coordinates of } \\
\text { Earth Conductors }\end{array}$} \\
\hline & & \multicolumn{2}{|c|}{ L1 } & \multicolumn{2}{|c|}{ L2 } & \multicolumn{2}{|c|}{ L3 } & \multicolumn{2}{|c|}{ E1 } & \multicolumn{2}{|c|}{ E2 } \\
\hline & & $x$ & $y$ & $x$ & $y$ & $x$ & $y$ & $x$ & $y$ & $x$ & $y$ \\
\hline \multirow{2}{*}{ Line 1} & Circuit I (220 kV) & -4.5 & 37 & -8 & 30.5 & -5 & 24 & \multirow[b]{2}{*}{0} & \multirow{2}{*}{45} & \multirow{2}{*}{-} & \multirow{2}{*}{ - } \\
\hline & Circuit II $(220$ kV) & 5 & 24 & 8 & 30.5 & 4.5 & 37 & & & & \\
\hline \multirow{3}{*}{ Line 2} & Circuit I (400 kV) & -9 & 66.2 & 0 & 66.2 & 9 & 66.2 & \multirow{3}{*}{-9.6} & \multirow{3}{*}{86.2} & \multirow{3}{*}{9.6} & \multirow{3}{*}{86.2} \\
\hline & Circuit II (400 kV) & 9 & 56.6 & 0 & 56.6 & -9 & 56.6 & & & & \\
\hline & Circuit III (220 kV) & -9.25 & 47 & 0 & 47 & 9.25 & 47 & & & & \\
\hline \multirow{3}{*}{ Line 3} & Circuit I (400 kV) & 6.8 & 44.8 & 6.9 & 34.3 & 7 & 23.8 & \multirow{3}{*}{-1.1} & \multirow{3}{*}{53.1} & \multirow{3}{*}{4.1} & \multirow{3}{*}{53.1} \\
\hline & Circuit II $(110$ kV) & -3.3 & 47 & -3.4 & 42.1 & -3.5 & 37.2 & & & & \\
\hline & Circuit III (110 kV) & -3.5 & 32.2 & -3.6 & 27.4 & -3.6 & 22.5 & & & & \\
\hline
\end{tabular}

\section{Requirements for the Construction of Multi-Circuit, Multi-Voltage Lines}

Conductors in overhead lines are tensioned between 10\% to 30\% of their rated tensile strength (RTS), and at the time of installation, the conductors are at a temperature between 5 and $30^{\circ} \mathrm{C}$. During their operating lifetime, planned for several years, phase conductors may reach high temperatures during periods of high electrical loading in the summer. Both phase conductors and the earth conductors are periodically exposed to high mechanical loads. Moreover, significant mechanical load and conductor swing occurs during strong winds and winter conditions characterized by frost and icing. In each of these cases, reliable and environmentally safe operating conditions of the overhead line must be maintained throughout the entire service life [9]. The mechanical calculations of the overhead lines carried out at the design stage are intended to determine the initial values of the tensions and sags that will meet the requirements described above, and also being optimized with respect to the investment costs required to build the line.

In the Polish $400 \mathrm{kV}$ and $220 \mathrm{kV}$ overhead lines, the rated span length is $450 \mathrm{~m}$, while in the case of $110 \mathrm{kV}$ lines, nominal span lengths are equal to $300 \mathrm{~m}$. The real span lengths are close to the values mentioned above and largely depend on the terrain conditions, which include factors such as the type of crossed objects, the allowable level of wind force acting on the pylons, as well as the tensile strength of the conductors. The construction of a multivoltage line with different types of conductors requires the optimal selection of the span lengths through the optimal arrangement of pylons along the line route. Proper selection of the span length should take into account the coordination of conductor sags while maintaining the required vertical distances and not exceeding the permissible percentage of the rated tensile strength of the conductor, defined by the normative guidelines. One of the possible solutions, in the case of selecting the span length in multi-voltage lines with different types of conductors, is to select a span corresponding to $110 \mathrm{kV}$ lines, i.e., a span length of approximately $(300 \div 350)$ meters, and an AFL- $6240 \mathrm{~mm}^{2}$ conductor type with an RTS value of $82.8 \mathrm{kN}$. For this approach, in the $110 \mathrm{kV}$ line, a conductor tensile stress of $100 \mathrm{MPa}$ can be used, which corresponds to typical $110 \mathrm{kV}$ lines, while the conductor tensile stresses for other voltage levels should be selected to maintain the required internal insulation gaps. An alternative solution is to assume the span lengths corresponding to the $400 \mathrm{kV}$ lines, which necessitate an increase in the tension of the $110 \mathrm{kV}$ line conductors to maintain the required vertical distances, assuming the $110 \mathrm{kV}$ line is suspended on the lower cross arm of the tower. The observations made so far on the optimal selection of the span length suggest the latter option is preferable, i.e., a suspension of the $110 \mathrm{kV}$ circuit on the tower's lowest cross arm with high conductor tensile stress. A comparison of the sag values at $80{ }^{\circ} \mathrm{C}$ under the assumption that the conductor is coated by ice at $-5{ }^{\circ} \mathrm{C}$ 
for two actual extraction sections of the Polish four-circuit, three-voltage line, with span lengths similar to both described variants, is presented in Tables 3 and 4 . According to our calculations, the AFL-6 $240 \mathrm{~mm}^{2}$ conductor's sag in a $454 \mathrm{~m}$ span at $80{ }^{\circ} \mathrm{C}$ is $16.84 \mathrm{~m}$.

Table 3. Sags in a four-circuit line in two tensioning sections with different span lengths at a temperature of $80^{\circ} \mathrm{C}$.

\begin{tabular}{|c|c|c|c|c|c|c|c|}
\hline \multirow{3}{*}{$\begin{array}{l}\text { Span Length } \\
\text { (m) }\end{array}$} & \multicolumn{3}{|c|}{$\operatorname{Sag}_{+80^{\circ} \mathrm{C}}(\mathrm{m})$} & \multirow{3}{*}{$\begin{array}{c}\text { Span Length } \\
\text { (m) }\end{array}$} & \multicolumn{3}{|c|}{$\operatorname{Sag}_{+80^{\circ} \mathrm{C}}(\mathrm{m})$} \\
\hline & $\begin{array}{c}\text { Circuit } 400 \mathrm{kV} \\
3 \times \text { AFL-8 } \\
350 \mathrm{~mm}^{2}\end{array}$ & $\begin{array}{c}\text { Circuit } 220 \\
\text { kV AFL-8 } \\
525 \mathrm{~mm}^{2}\end{array}$ & $\begin{array}{l}\text { Circuit } 110 \\
\text { kV AFL-6 } \\
240 \mathrm{~mm}^{2}\end{array}$ & & $\begin{array}{c}\text { Circuit } 400 \mathrm{kV} \\
3 \times \text { AFL-8 } \\
350 \mathrm{~mm}^{2}\end{array}$ & $\begin{array}{c}\text { Circuit } 220 \\
\text { kV AFL-8 } \\
525 \mathrm{~mm}^{2}\end{array}$ & $\begin{array}{c}\text { Circuit } 110 \\
\text { kV AFL-6 } \\
240 \mathrm{~mm}^{2}\end{array}$ \\
\hline & $51.12 \mathrm{MPa}$ & $50.86 \mathrm{MPa}$ & $52.84 \mathrm{MPa}$ & & $43.31 \mathrm{MPa}$ & $45.60 \mathrm{MPa}$ & $44.47 \mathrm{MPa}$ \\
\hline 454 & 16.61 & 16.71 & 16.84 & 355 & 11.98 & 11.39 & 12.23 \\
\hline 431 & 14.97 & 15.06 & 15.17 & 350 & 11.65 & 11.07 & 11.88 \\
\hline 439 & 15.53 & 15.62 & 15.74 & 340 & 10.99 & 10.45 & 11.22 \\
\hline 429 & 14.83 & 14.92 & 15.03 & 365 & 12.67 & 12.04 & 12.93 \\
\hline 439 & 15.53 & 15.62 & 15.74 & 355 & 11.98 & 11.39 & 12.23 \\
\hline
\end{tabular}

Table 4. Sags in a four-circuit line in two tensioning sections with different span lengths at a temperature of $-5^{\circ} \mathrm{C}$ with ice load.

\begin{tabular}{|c|c|c|c|c|c|c|c|}
\hline \multirow{3}{*}{$\begin{array}{c}\text { Span Length } \\
\text { (m) }\end{array}$} & \multicolumn{3}{|c|}{ Sag $_{-5}{ }^{\circ} \mathrm{C}+\mathrm{ice}(\mathrm{m})$} & \multirow{3}{*}{$\begin{array}{c}\text { Span Length } \\
\text { (m) }\end{array}$} & \multicolumn{3}{|c|}{ 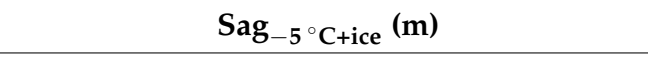 } \\
\hline & $\begin{array}{c}\text { Circuit } 400 \mathrm{kV} \\
3 \times \text { AFL-8 } \\
350 \mathrm{~mm}^{2}\end{array}$ & $\begin{array}{c}\text { Circuit } 220 \\
\text { kV AFL-8 } \\
525 \mathrm{~mm}^{2}\end{array}$ & $\begin{array}{c}\text { Circuit } 110 \\
\text { kV AFL-6 } \\
240 \mathrm{~mm}^{2}\end{array}$ & & $\begin{array}{c}\text { Circuit } 400 \mathrm{kV} \\
3 \times \text { AFL-8 } \\
350 \mathrm{~mm}^{2}\end{array}$ & $\begin{array}{l}\text { Circuit } 220 \\
\text { kV AFL-8 } \\
525 \mathrm{~mm}^{2}\end{array}$ & $\begin{array}{c}\text { Circuit } 110 \\
\text { kV AFL-6 } \\
240 \mathrm{~mm}^{2}\end{array}$ \\
\hline & $104.7 \mathrm{MPa}$ & $96.7 \mathrm{MPa}$ & $115 \mathrm{MPa}$ & & $92 \mathrm{MPa}$ & $91.5 \mathrm{MPa}$ & $100 \mathrm{MPa}$ \\
\hline 454 & 14.18 & 13.97 & 14.81 & 355 & 9.86 & 9.02 & 10.42 \\
\hline 431 & 12.78 & 12.59 & 13.35 & 350 & 9.59 & 8.76 & 10.13 \\
\hline 439 & 13.26 & 13.06 & 13.85 & 340 & 9.05 & 8.27 & 9.56 \\
\hline 429 & 12.66 & 12.47 & 13.23 & 365 & 10.43 & 9.53 & 11.01 \\
\hline 439 & 13.26 & 13.06 & 13.85 & 355 & 9.86 & 9.02 & 10.42 \\
\hline
\end{tabular}

By subtracting the length of the insulator string $(1.3 \mathrm{~m})$ and the sag $(16.84 \mathrm{~m})$ from the height of the lower cross arm of the tower $(24 \mathrm{~m})$, a vertical distance of $5.86 \mathrm{~m}$ is obtained. This value is almost equal to the required minimum distance of the $110 \mathrm{kV}$ line conductors from the ground, as defined by the European standard [4] for overhead lines (the required value is $5.85 \mathrm{~m}$ ). The solution based on the use of long spans and high conductor tensile strength value imposes the constraint that the distances of the $110 \mathrm{kV}$ circuit conductors to the ground are kept very small. The highest applied conductor tension must not exceed 40\% of the conductor's RTS in normal tensioning sections. The basic conductor stress applied is equal to $115 \mathrm{MPa}$ in the circuit with the AFL-6240 $\mathrm{mm}^{2}$ conductor and corresponds to a conductor tension equal to $38 \%$ RTS. A recommended solution could be building the $110 \mathrm{kV}$ circuit with the AFL- $8525 \mathrm{~mm}^{2}$ conductor, which would ensure the required ground distances while maintaining lower tension values in the conductor. The second possible solution is to use shorter span lengths while maintaining the AFL- $6240 \mathrm{~mm}^{2}$ conductor in the $110 \mathrm{kV}$ line circuit. Such an approach would require a larger number of towers in an indicated line, but it also has the positive effect of increasing the external clearances to the ground.

The practical experience gleaned from the construction of overhead lines with several voltage levels shows that the dominant solution is to place the circuits with the highest voltage $(400 \mathrm{kV})$ on the highest cross arms, while the conductors of circuits with a lower voltage $(220 \mathrm{kV}, 110 \mathrm{kV})$ are suspended on the lower cross arms of the tower. This solution results in minimizing the risk of damaging the $400 \mathrm{kV}$ line caused by breaking the $110 \mathrm{kV}$ line conductor. It is accepted that the $400 \mathrm{kV}$ network is more reliable, and thus the higher suspension of the $400 \mathrm{kV}$ circuit will ensure that a break of the conductor in the $110 \mathrm{kV}$ circuit will not lead to the risk of a line-to-line short circuit between these two 
voltage levels. An additional aspect that supports the placement of the highest voltage circuits on the highest cross arms is the phenomena of mutual compensation in the electric components caused by the interaction of electromagnetic fields under the overhead line, which occurs due to the presence of circuits with different voltage levels. Such an arrangement allows expansion of the width of the technological route to 44 meters, while in the double-circuit $400 \mathrm{kV}$ line, the width of the required technological route is $70 \mathrm{~m}$. The determined technological route width is also impacted by the tower's allowable internal dimensions. Requirements for internal clearances are implemented through the appropriate selection of the tower's silhouette dimensions and the length of the insulator strings' length. Maintaining the required distances between the conductors and the tower's axis is achieved through a proper extension of the cross arm. Internal clearances largely depend on the rated voltage level as well as the terrain conditions through which the overhead line is led. Practical experience shows that the steel towers used in multi-circuit, multi-voltage lines are constructed symmetrically, with cross arms of the same length on both sides of the tower.

Furthermore, it can be shown that for lines covering three voltage levels $(400 \mathrm{kV}$, $220 \mathrm{kV}$, and $110 \mathrm{kV}$ ), the geometric clearances of the insulation gaps for a $110 \mathrm{kV}$ line are often the same as for a $220 \mathrm{kV}$ line. Such a solution has a slight impact on the construction cost of the line, but in the future, due to the activities in the field of transmission network development, this will easily allow for the use of the existing $110 \mathrm{kV}$ line to operate at $220 \mathrm{kV}$. Increasing the $110 \mathrm{kV}$ circuit voltage in this case will be possible after the working conductor is replaced (as a result of the corona phenomenon), as well as after the insulating elements are also replaced with equipment dedicated to $220 \mathrm{kV}$ lines.

\section{Electromagnetic Field around the Multi-Circuit, Multi-Voltage Transmission Lines}

An important issue related to the use of overhead transmission lines is the electromagnetic fields that the lines produce in their vicinity and the impact of environmental exposures to these fields. The importance of this subject is evidenced by numerous scientific publications, including $[10,11]$. The relationship between the intensity of the electromagnetic field and the potential effects of its influence on living organisms, in particular humans, is of special interest to organizations such as ICNIRP (International Commission on Non-Ionizing Radiation Protection), IEEE (Institute of Electrical and Electronics Engineers), Council of the European Union, and WHO (World Health Organization).

High-voltage overhead lines are objects covering large areas of land where people may reside. For this reason, in some countries, including Poland, detailed regulations have been developed that specify the conditions for constructing high-voltage overhead lines to limit the strength of electromagnetic fields around them. Currently, the electromagnetic field strength limits for the transmission and distribution network elements operating at $50 \mathrm{~Hz}$ frequency in selected countries are based on the ICNIRP document [12,13]. The ICNIRP organization defines the limit of the electric field strength (reference point) at the level of $5 \mathrm{kV} / \mathrm{m}$ with no additional time restrictions. The limit value of the magnetic field strength, also without any time constraints, is $80 \mathrm{~A} / \mathrm{m}$. The recommendations set out by the Council of the European Union in 1991/519/EC are the same as the ICNIRP guidelines. These values have been adopted as national standards in countries worldwide, including France, Switzerland, Great Britain, Austria, Czech Republic, Croatia, and Portugal. More detailed regulations have been established in Germany, where an electric field strength of $10 \mathrm{kV} / \mathrm{m}$ is allowed for short-term use in fields and small areas of undeveloped land; in all other areas, the upper limit is $5 \mathrm{kV} / \mathrm{m}$. In the case of magnetic field strength, it is allowed to reach values as high as $120 \mathrm{~A} / \mathrm{m}$ for up to $1 \mathrm{~h}$ per day; otherwise, the permissible field strength is $80 \mathrm{~A} / \mathrm{m}$. In the United States, there are various laws depending on the state; for example, for the state of New York, field strength limits are defined at the edge $(1.6 \mathrm{kV} / \mathrm{m}$ and $16 \mathrm{~A} / \mathrm{m})$ and inside $(11.8 \mathrm{kV} / \mathrm{m}$ and $16 \mathrm{~A} / \mathrm{m})$ of the technological route of the transmission line. According to the Polish standards in [14] and [15], permissible levels for places accessible to people for the electric and magnetic field strengths are $10 \mathrm{kV} / \mathrm{m}$ and 
$60 \mathrm{~A} / \mathrm{m}$, respectively, and in the areas designated for housing development, the electric field strength must not exceed $1 \mathrm{kV} / \mathrm{m}$.

The value of the transmission line's electromagnetic field strength is primarily determined by the geometry of the conductor configuration, the rated voltage, and the line load. The current problems facing expansions of the network infrastructure are mainly based on social opposition resulting from anxiety about electromagnetic impact of high voltage overhead transmission lines. Since multi-circuit, multi-voltage lines have larger dimensions than single- or double-circuit lines, the social concerns about their construction are even greater. For this reason, the determination and publication of such values are especially important.

The Polish transmission network development plan [8] provides for the liquidation of Line 1 and the construction of Line 2 in its place. For this reason, a comparison of the electromagnetic field profiles for a double-circuit, single-voltage line (Line 1) and a three-circuit, double-voltage line (Line 2) are shown.

The method used to determine the electromagnetic field strength in the vicinity of the overhead transmission lines is described, among others, in [16,17]. We calculated the electric and magnetic field strengths using our mathematical model based on the methods proposed in $[16,17]$. The model was implemented in the MATLAB program. The calculations were carried out using location coordinates of phase and ground conductors (Table 2) and by considering the conductors' sag and the insulators' length. The line capacitances, which the electric field strength depends on, were determined as described in Section 4.3 of this article. To determine the magnetic field strength, we assumed the maximum values of the long-term permissible currents, i.e., $2850 \mathrm{~A}$ for $400 \mathrm{kV}$ circuits and $1220 \mathrm{~A}$ for $220 \mathrm{kV}$ circuits. The obtained results (Figure 1) were additionally verified in the MicroTran program, and the obtained results were the same.

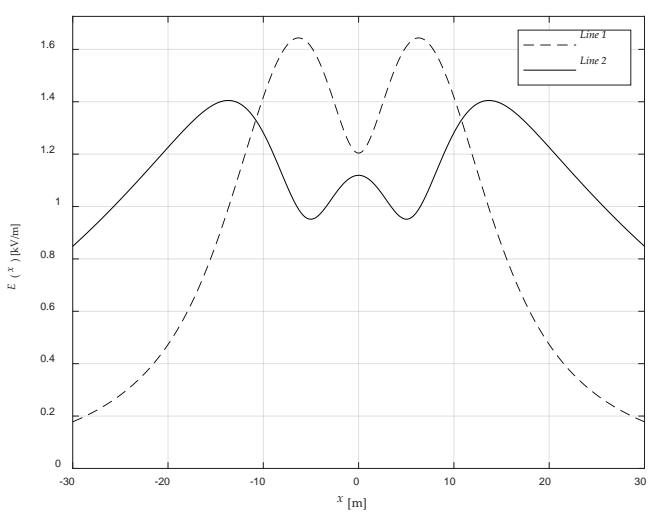

(a)

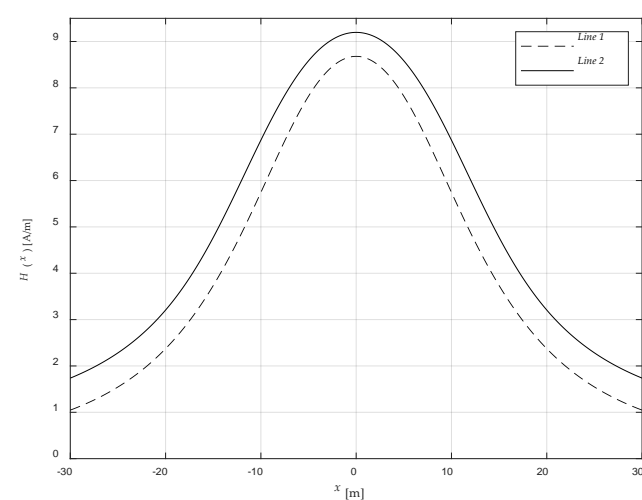

(b)

Figure 1. Graphs of (a) electric field strength $E$ and (b) magnetic field strength $H$ of two types of multi-circuits (Line 1 and Line 2 from Table 2).

Figure $1 \mathrm{a}, \mathrm{b}$ shows one of the exemplary sets of the calculated electric field strength $E$ and magnetic field strength $H$ determined as a function of the distance from the tower axis. The electromagnetic field profiles were determined at positions where there is the lowest position of the conductors in the span, at the height of $2 \mathrm{~m}$ from the earth's surface, which is usually given as the standard value.

The magnetic field strength is much lower than the established limit value for both transmission line structures, even though it was determined while assuming the line's full load with long-term permissible currents. The profile of the $H$-field is similar for both line construction types considered, as evidenced by the curves shown in Figure $1 \mathrm{~b}$. For the electric field $E$, a lower maximum value was found for Line 2 than for Line 1, despite the higher rated voltage of Line 2 (Figure 1a). According to Polish regulations, the value of $E(1 \mathrm{kV} / \mathrm{m})$ is achieved at approximately $14 \mathrm{~m}$ from the tower axis for Line 1 and 
approximately $25 \mathrm{~m}$ from the tower axis for Line 2 . These values are still within the width of the technological routes of transmission lines. Based on these results and other cases, it should be stated that, with the appropriate arrangement of the phase conductors, using a multi-circuit, multi-voltage line does not exceed the conditions set for the electromagnetic field, and thus there is no additional impact on the environment.

\section{Mathematical Model of Multi-Circuit, Multi-Voltage Transmission Lines}

The mathematical models of overhead lines are widely described in the literature [18-20]. Depending on the needs, these models are used in a simplified or exact form for different types of analysis.

A detailed mathematical description of three-phase lines is quite complicated due to the earth's presence as a conducting plane, the inductive and capacitive couplings between the line's individual conductors, and their spatial distribution. A significant simplification can be applied when the model is used for steady states (power flows) and quasi-steady states (e.g., short-circuits) analyses. On this basis, the following were assumed:

- the transmission line is a linear element, i.e., the voltages and currents are mutually linear combinations;

- the line conductors and earth create earth-return circuits;

- $\quad$ the line is phase symmetrical;

- the line is symmetrical to its ends;

- line leakage is omitted;

- $\quad$ line capacitances are determined and included in the model as a result of separate analysis; and

- $\quad$ line capacitances are concentrated at its ends.

As a result of the simplifications applied, the mathematical models of symmetric lines in the form of pi-type with lumped series parameters (resistance $R$ and reactance $X$ ) and shunt parameters (susceptance $B$ ) for symmetrical components of positive-, negative-, and zero-sequences are used. The series parameters $R$ and $X$ were determined from the earth-return circuits' self and mutual impedances $Z$, while the shunt parameters $B$ are based on Maxwell's potential coefficients $P$. The line model is applied to the transmission network model by including the structural and geometric parameters in the admittance matrices. The method of determining the electrical parameters of transmission line model will be presented later in this paper.

In high voltage overhead lines, the phase conductors are often sets of individual $m$ conductors connected in parallel and arranged in a uniform geometric configuration, called bundle conductors. Additionally, high voltage transmission lines are equipped with earth conductors. To limit the number of equations used to describe the line, the model will be further simplified as follows. First, according to [18], the creation of a common reference node allows the earth to be eliminated by transferring its impedance to the phase conductors. Second, within each phase, where bundle conductors are used, we assumed an equal voltage of all nodes belonging to the same bundle, as well as an even phase current distribution over the conductors in the bundle, which allows us to aggregate bundle conductors into a single, equivalent conductor. The last simplification treats earth conductors as closed earth-return circuits with zero voltage at their ends. This approach is justified by the fact that the earth conductors are grounded at each tower, and the ends of the overhead line and the high values of the tower grounding resistance relative to the end substations' grounding resistances. The effect of the described simplifications is shown schematically in Figure 2. 


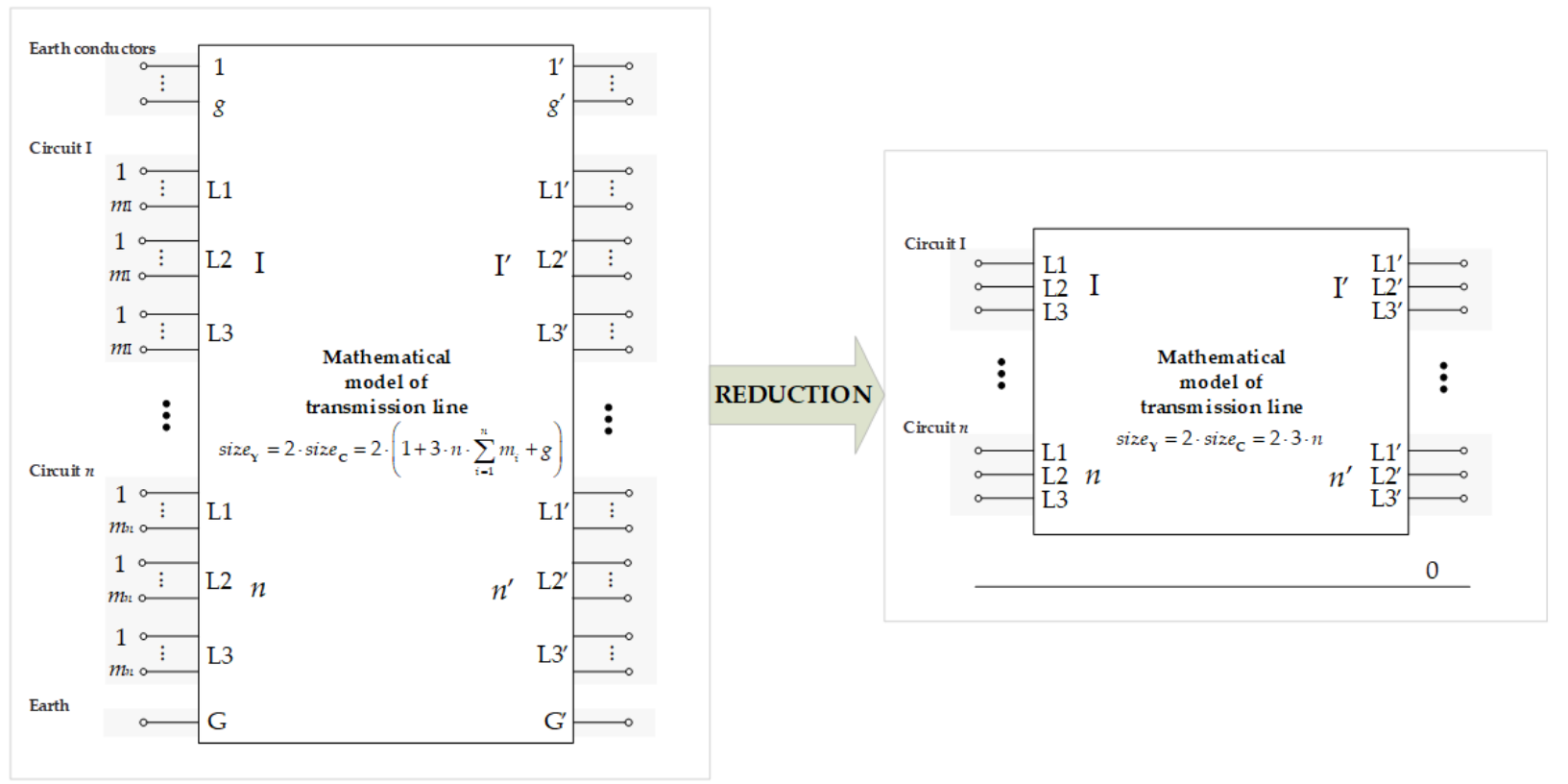

Figure 2. Block diagram of the multi-circuit line before and after simplification operations.

The inversion of the $\mathbf{Z}$ and $\mathbf{P}$ matrices corresponds to the admittance matrices $\mathbf{Y}$ and C, respectively, whereby the susceptance $\mathbf{B}$ of the transmission line is determined by the relation (1):

$$
\mathbf{B}=\omega \mathbf{C}
$$

It is necessary for the mathematical description of transmission lines in the network structure to convert its parameters into relative units. This operation is particularly important for overhead lines with multi-voltage construction. Usually, for base voltages the rated voltages are adopted, and for the base power the same value for all circuits is used. The reference base determination of the admittance parameters of this model, in relative units, are described by Equations (2) and (3):

$$
\begin{gathered}
Y_{\mathrm{b} i}=S_{\mathrm{b}} U_{\mathrm{b} i}^{-2} \\
Y_{\mathrm{b} i . j}=S_{\mathrm{b}}\left(U_{\mathrm{b} i} U_{\mathrm{b} j}\right)^{-1}
\end{gathered}
$$

where $Y_{\mathrm{b} i}$ is the self-admittance base parameter $(Y$ or $B)$ of the transmission line; $Y_{\mathrm{b} i . j}$ is the mutual admittance base parameter $(Y$ or $B)$ of the transmission line; $U_{\mathrm{b} i}$ is the base voltage of $i$-circuit of the $n$-circuit transmission line (where $i \in\{\mathrm{I}, \mathrm{II}, \ldots, n\}$ ); and $S_{\mathrm{b}}$ is the base power (we assumed a base power of $100 \mathrm{MV} \cdot \mathrm{A}$ ).

The phase impedance model of the transmission line is transformed into a model of symmetrical components; this method has been described in various works, e.g., in [18]. In the case of symmetric lines, the final diagonal positive- and negative-sequence admittance and susceptance matrices are obtained. As a result, the positive- and negative-sequence models' equivalent schemes correspond to independent line circuit models. The zerosequence model is described with full admittance and susceptance matrices representing the inductive and capacitive couplings between the distinct circuits in the multi-circuit lines. The process for determining this model is illustrated in Figure 3. 


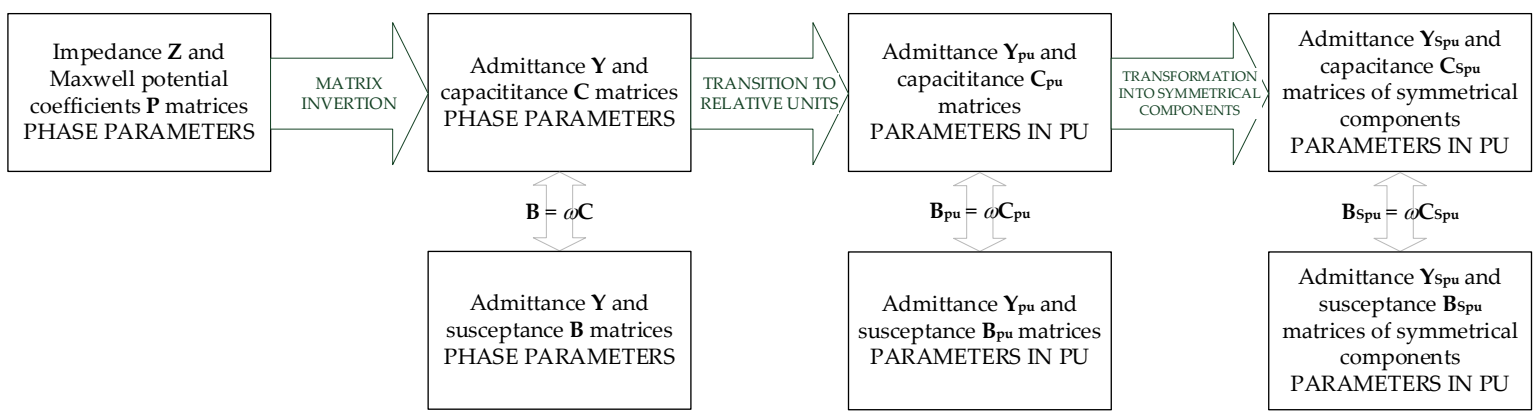

Figure 3. The process of determining the model of a multi-circuit, multi-voltage high voltage alternating current (HVAC) transmission line.

After determining line parameters (Sections 4.1 and 4.3), we performed two separate analyses for the series and shunt parameters (Sections 4.2 and 4.4, respectively) to illustrate the impact of their asymmetry on the multi-voltage transmission line operation. Section 5 considers the full transmission line model, which includes both series and shunt parameters.

\subsection{Transmission Line Series Parameters}

The estimates of the series parameters of high voltage overhead transmission lines is based on the earth-return circuits theory. In terms of an overhead transmission line, an earth-return circuit is an overhead conductor suspended above the earth's surface and supplied with a voltage source at one end and grounded at the other end. In earth-return circuits, the earth, treated as a conductive plane, is the return conductor, and the line phase and earth conductors are treated as parallel closed earth-return circuits. The earth-return circuits are described by self-impedance $Z_{\mathrm{W}}$ and mutual impedance $Z_{\mathrm{M}}$.

The self-impedance is due to the electromagnetic field penetrating the conductor and an induced rotating electric field around the conductor because of current flow. The value of the self-impedance for a single conductor operating at $50 \mathrm{~Hz}$ frequency in $\Omega / \mathrm{km}$ is given by Relation (4) [18-20]:

$$
\mathrm{Z}_{\mathrm{W}}{ }^{\prime}=R_{c^{\prime}}+0.049+\mathrm{j} 0.145 \log \frac{\delta}{r_{0}}
$$

where $R_{c}{ }^{\prime}$ is the unit self-resistance of the conductor (in $\Omega / \mathrm{km}$ ); $\delta$ is the distance of the overhead conductor from the fictitious equivalent conductor placed in the earth (in $\mathrm{m}$ ); and $r_{0}$ is the characteristic radius of a single conductor (in $\mathrm{m}$ ).

The mutual impedance is caused by the influence that other conductors have on the overhead conductor being considered. The mutual impedance between any two conductors $a$ and $b$ is determined by the quotient of the potential difference at the terminals of the open and grounded circuit $b$ and the current $I_{a}$ that flows through the supplied circuit $a$, which is the source of the voltage appearing at conductor $b$ terminals. The mutual impedance for conductors operating at $50 \mathrm{~Hz}$ frequency (in $\Omega / \mathrm{km}$ ) is equal to

$$
\mathrm{Z}_{\mathrm{M}^{\prime}}=0.049+\mathrm{j} 0.145 \frac{\delta}{D}
$$

where $D$ is the average geometric distance between the discussed conductors $a$ and $b$ [18-20].

In the case of multi-circuit lines, magnetic couplings are distinguished between the individual circuits of the line. Mutual impedances between the conductors of two different circuits are determined according to the relation (5), where $D$ is the average geometric distance between the phase conductors in the circuits being considered. The earth conductors are treated in the same way.

The equivalent schemes of a three-circuit, double-voltage transmission line (Table 2, Line 2) are presented in Figure 4. The symmetrical component's series parameters and the 
admittance model $\mathbf{Y}_{\text {Spu }}$ for the positive-, negative- $\left(\mathbf{Y}_{2 \mathbf{p u}}=\mathbf{Y}_{1 \mathbf{p u}}\right)$, and zero-sequence $\left(\mathbf{Y}_{\mathbf{0 p u}}\right)$ were determined using the previously described assumptions and procedure (Figure 3).

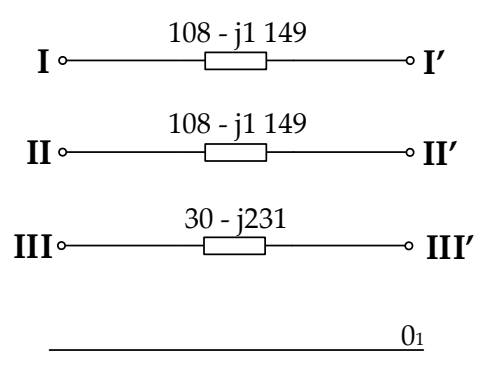

(a)

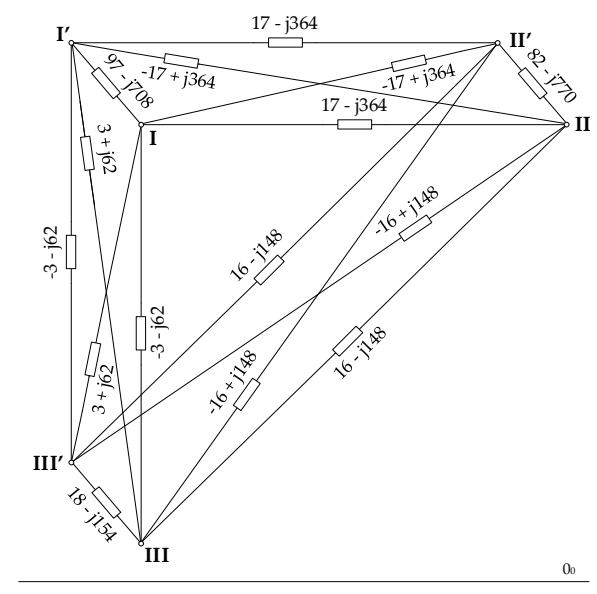

(b)

Figure 4. Schemes of Line 2 (a) positive- (negative-) and (b) zero-sequence [21] (parameters in pu).

\subsection{Analysis of Impedance Asymmetry}

Obtaining full impedance symmetry requires making $9 n$ single transpositions of phase conductors, where the term single transposition is understood as changing the position of two selected phase conductors of the line. Due to the conductor configuration in the line and the different voltage levels of the individual circuits, it is a technically and logistically complicated process. The cost aspect should also be considered because usually for lines with more circuits, the transposition of phase conductors requires an additional tower, which increases the costs of line construction. Thus, due to these drawbacks, line symmetrization by the transposition of its phase conductors is typically not pursued.

In the case of asymmetrical lines, in which the transposition of phase conductors is not applied, the admittance matrix of symmetrical components $\mathbf{Y}_{\mathbf{S}}$ is a complete, full matrix. Supplying the line with a positive-sequence voltage and loading only with a positivesequence current yields voltages of all symmetrical components (positive-, negative-, zero-sequences).

To determine the expected line impedance asymmetry and its effect on the transmission network's ability to meet the quality requirements for the delivered electrical energy, the zero-sequence voltage values at the end of the unloaded circuit with the lowest rated voltage were determined. The analysis was performed for two actual three-circuit, doublevoltage lines with various geometric asymmetries operating in the Polish system, i.e., Line 2 and Line 3. Asymmetric lines were supplied with symmetrical positive-sequence voltage in nodes I, II, and III and loaded with positive-sequence currents in nodes I' and II' with magnitudes equal to the long-term permissible current values of each circuit. The value of the zero-sequence voltage was determined as a function of the position of the extreme phases of Circuit III. The external conductors of Circuit III were moved symmetrically on both sides of the tower axis (Figure 5a) to determine the value of the zero-sequence voltage induced in this circuit per one kilometer of the line length (Figure $5 b$ ). The influence of earth conductors on the value of the zero-sequence voltage is noticeable. Over the entire range of changes, earth conductors reduce the value of the inducted zero-sequence voltage $U_{0}$. 


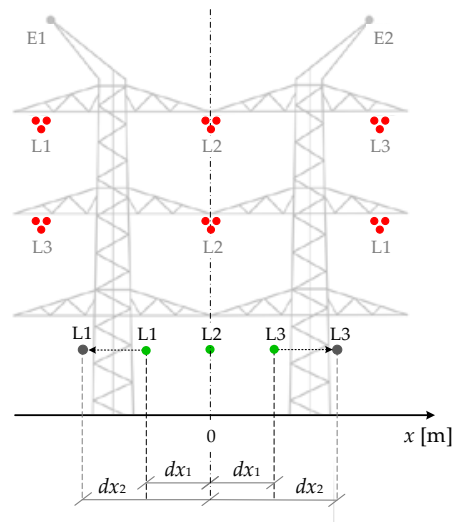

(a)

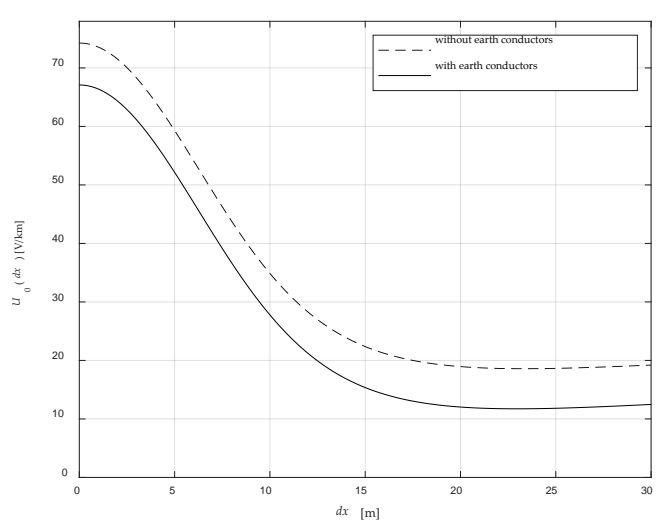

(b)

Figure 5. Analysis of impedance asymmetry of Line 2: (a) Horizontal phase conductor configuration of Line 2, with $d x_{1}$ and $d x_{2}$ as examples of two extreme phase conductors of Circuit III positions. (b) The voltage $U_{0}$ as a function of extreme phase location calculated per one kilometer of the line length in a horizontal phase conductor configuration of Line 2.

A similar analysis was performed for a double-circuit line with a vertical phase conductor configuration (Table 2, Circuit I and Circuit III of Line 3). The $110 \mathrm{kV}$ voltage circuit position was continuously changed so that in extreme positions, this circuit was the lower $\left(d y=d y_{\min }=0 \mathrm{~m}\right)$ and upper $\left(d y=d y_{\max }=14.7 \mathrm{~m}\right)$ circuit of the real three-circuit line (Figure 6a), with $d y$ denoting the absolute difference in the suspension height of the analyzed $110 \mathrm{kV}$ circuit and Circuit II of Line 3 (Table 2). We noted a positive influence of earth conductors as they reduce the induced zero-sequence voltage as the lower circuit approaches the earth conductors (Figure $6 \mathrm{~b})$. In the extreme position $\left(d y_{\max }=14.7 \mathrm{~m}\right)$, the voltage $U_{0}$ is reduced by about $100 \mathrm{~V}$ per one kilometer of the line length. The earth conductors have a beneficial effect on the top of the Line 3 circuit and an adverse effect on the bottom circuit.

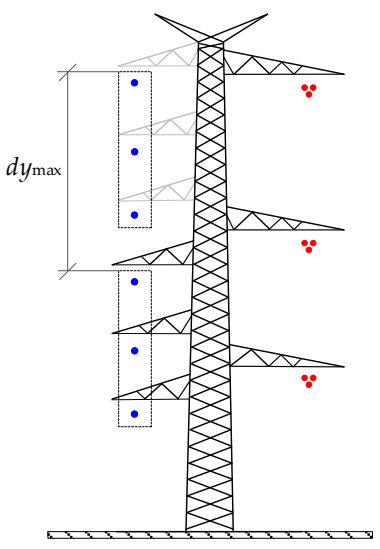

(a)

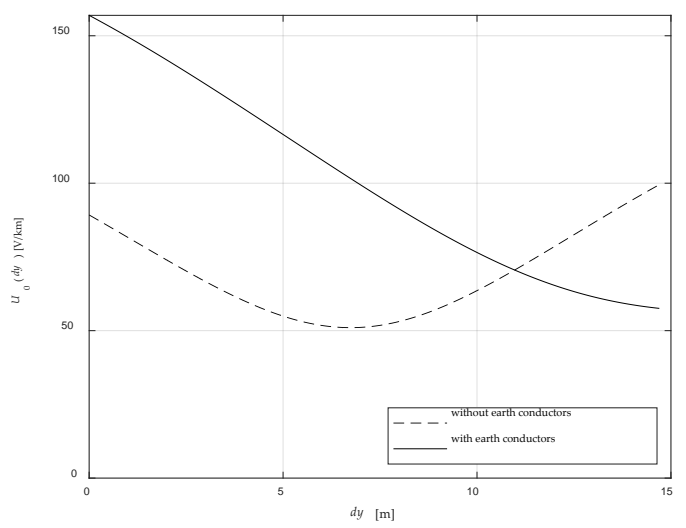

(b)

Figure 6. Analysis of impedance asymmetry of Line 3: (a) A scheme of the silhouette of the Line 3 tower. (b) The zero-sequence component of voltage $U_{0}$ as a function of the $110 \mathrm{kV}$ circuit location $d y$ from the lower $(d y=0 \mathrm{~m})$ to the upper $\left(d y_{\max }=14.7 \mathrm{~m}\right)$ position.

For long asymmetrical lines, the zero-sequence voltage value may exceed the limit values. As a result, it tends to exceed the permissible values of voltage quality factors.

In addition, the analysis of individual impedance symmetrical components' values for the symmetrical and asymmetrical transmission line model shows significant differences, 
which may impact the short-circuit impedance values calculated in systems with multicircuit, multi-voltage lines. Such an analysis is presented in Section 5 of this paper.

\subsection{Transmission Line Shunt Parameters}

An overhead line's capacitance is determined based on the charges on its conductors' and these conductors' potentials, using the mirror reflection method [18-20]. Similarly, as for the series parameters, the self and mutual parameters are calculated in the form of Maxwell's potential coefficients by determining the ratio of the conductor potential to the density of the charge accumulated on it. These dependencies result from simple electrode systems (cylinder-cylinder) and are calculated based on geometric dimensions and material constants of conductors, resulting in the following:

$$
\begin{aligned}
& P_{a a}=\frac{1}{2 \pi \varepsilon_{0} l} \ln \frac{2 h_{a}}{r_{a}} \\
& P_{a b}=\frac{1}{2 \pi \varepsilon_{0} l} \ln \frac{d_{a b^{\prime}}}{d_{a b}}
\end{aligned}
$$

where $\varepsilon_{0}$ is the electric constant permittivity of vacuum (in $\mathrm{F} / \mathrm{m}$ ); $l$ is the length of conductor (in $\mathrm{m}$ ); $r_{a}$ is the radius of conductor $a$ (in $\mathrm{m}$ ); $h_{a}$ is the suspension height of conductor $a$ above the earth's surface (in m); $d_{a b}$ is the distance between conductor $a$ and $b$; and $d_{a b}$ is the distance of the conductor $a$ from the mirror image of the conductor $b$. The potential coefficient $P_{a a}$ applies to the given conductor $a$, while the coefficient $P_{a b}$ corresponds to the pair of conductors $a$ and $b$. As mentioned earlier, the inversion of the matrix of the transmission line's potential coefficients $\mathbf{P}$ yields the capacitance of this line $\mathbf{C}$.

The capacitance matrix $\mathbf{C}$ is an admittance type matrix. The off-diagonal elements of matrix $\mathbf{C}$, taken with the opposite sign, are the capacitance values between the given phase conductor pair. The self-capacitance of conductor $a$ is determined as the sum of the elements in row $a$ of this matrix.

Similar to the series parameters, in Figure 7 we show the schemes of symmetrical component capacitances, namely the positive $\left(\mathbf{C}_{\mathbf{1 p u}}\right)$, negative $\left(\mathbf{C}_{\mathbf{2 p u}}=\mathbf{C}_{\mathbf{1 p u}}\right)$, and zerosequence $\left(\mathbf{C}_{\mathbf{0 p u}}\right)$ of the three-circuit, double-voltage transmission line (Table 2, Line 2).

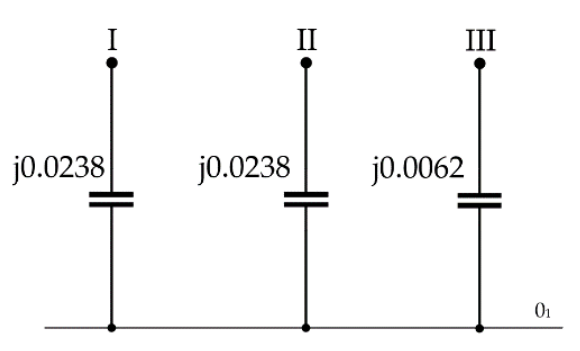

(a)

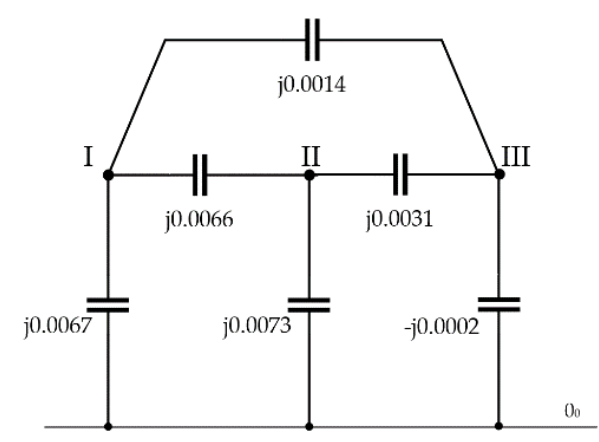

(b)

Figure 7. Schemes of Line 2 (a) positive- (negative-) and (b) zero-sequence (parameters in pu).

\subsection{Analysis of Capacitance Asymmetry}

As with the series parameters, the lack of phase symmetrization of the line leads to capacitance asymmetry. In the transmission lines with different voltages' ratings sharing the supporting structure, the line capacitance asymmetry is primarily noticeable for the lowest voltage networks. A similar situation was observed when there is a medium voltage line under the high voltage transmission line. Measurements and calculations presented in [22] show that the zero-sequence voltage in $15 \mathrm{kV}$ lines could be on the order of several kilovolts. This condition significantly hinders the operation of the medium voltage line due 
to the inability to electrically ground it. For high voltage transmission lines, the appearance of additional voltage may affect the incorrect operation of earth-fault protection and may result in the appearance of significant zero-sequence currents under normal operating conditions of the network.

The capacitance asymmetry's influence was determined by calculating the value of the zero-sequence voltage that appears in the lower voltage circuit when a higher voltage circuit is supplied. It should be emphasized that the zero-sequence voltage reduction effect will not occur in the case of transposition of the phase conductors in the circuit with a lower voltage. Here, the analysis was performed in the same way as the previous calculation of the series parameters for various conductors' positions in the circuit. For Line 2, the lowest (i.e., closest to zero) that induced a zero-sequence voltage appears when the extreme phase conductors of Circuit III (i.e., L1, L3) are $9 \mathrm{~m}$ away from the tower axis (Figure 8a), which is realized in the real transmission line (Table 2).

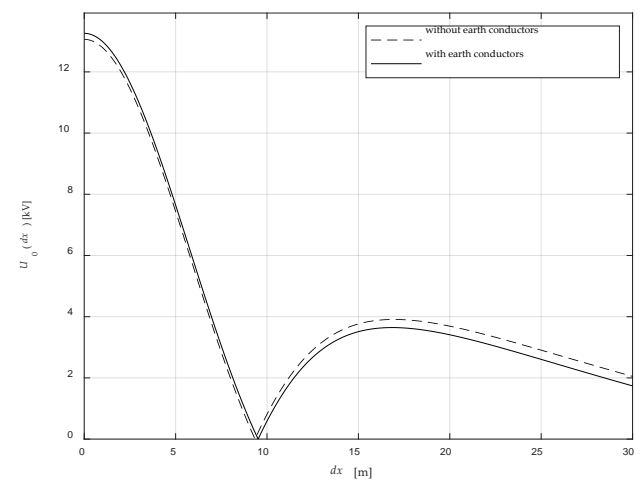

(a)

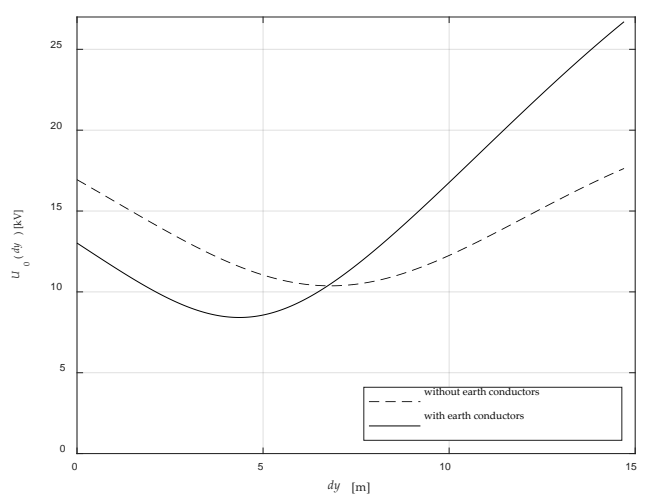

(b)

Figure 8. The voltage $U_{0}$ as a function of (a) location the extreme phases of Line 2; (b) the $110 \mathrm{kV}$ circuit location $d y$ from the lower $(d y=0 \mathrm{~m})$ to the upper $(d y=14.7 \mathrm{~m})$ position [23].

In the case of Line 3, a favorable impact of earth conductors can be observed (Figure 8b). The earth conductors' influence reduces the zero-sequence voltage in the range of changes $d y=(0 \div 7) \mathrm{m}$. Further increasing the circuit (changes in the range $d y=(7 \div 14.7) \mathrm{m})$ is characterized by a considerable influence of the earth conductors, causing an increase of the zero-sequence voltage value, in an extreme position, even by $10 \mathrm{kV}$.

\section{Analysis of a Multi-Circuit, Multi-Voltage Transmission Line in the Power System}

The consequence of the multi-circuit line's lack of geometric symmetry is the phase asymmetry of individual circuits and the appearance of voltage and current asymmetry in the power system. With short lines, the differences between the symmetric and the exact model are not large; therefore, in such cases, the simplified symmetric models can be used. With longer lines, simplified symmetrical models may lead to significant errors when estimating the asymmetry factors for operating loads or the distribution of these currents in individual phases of the line circuits.

For simulation purposes, the MATLAB Simulink program was used to model a three-circuit line operating in a power system (Figure 9). The three-circuit transmission line's model was realized using the basic $R, L, C$ elements available in the Simulink library. Corresponding values were determined based on the line conductors' geometric parameters and material constants, following the procedure described in Section 4 of this article. The external system was replaced with substitute sources from the line's supply-side (nodes I, II, III) and from the other side (nodes I', II', III') with loads of constant impedances. 


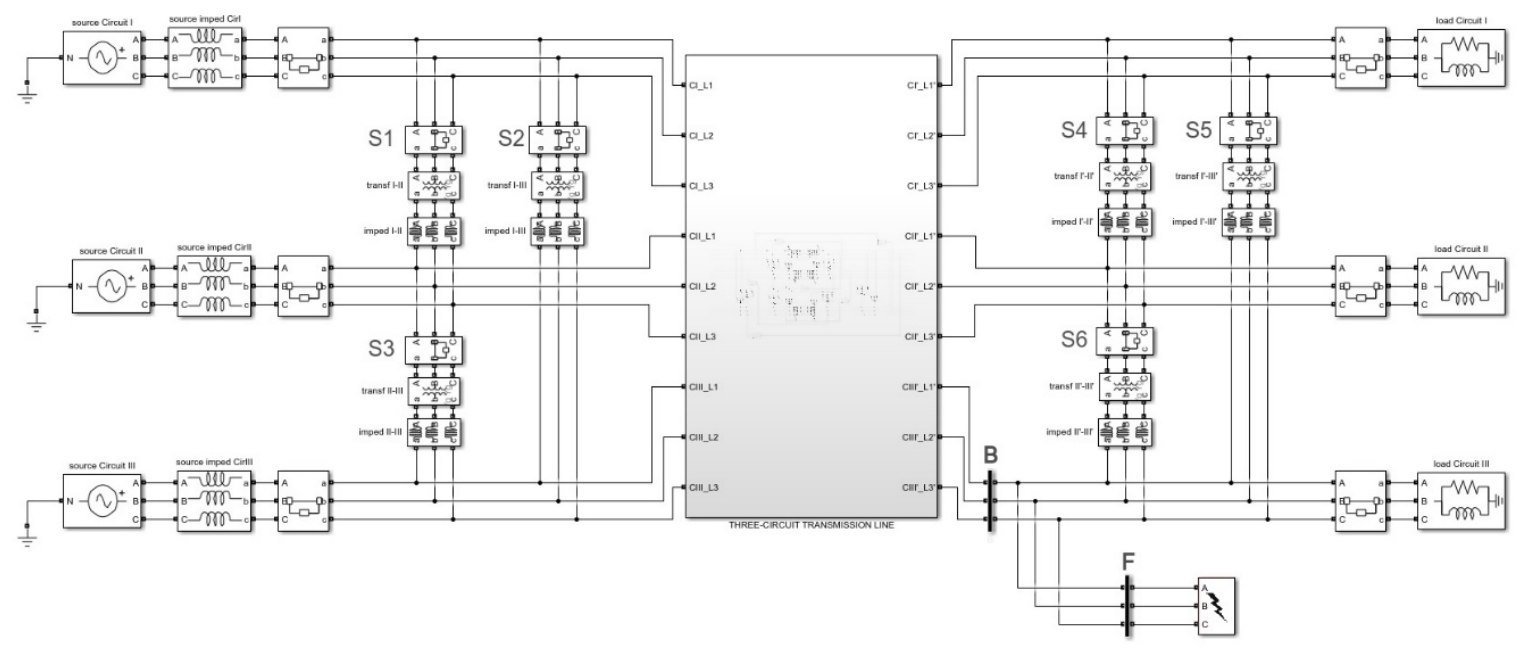

Figure 9. Transmission network model with a three-circuit transmission line designed in MATLAB Simulink program.

Initially, the full equivalent of the external network was modeled. The full equivalent model includes the connections of all nodes of the transmission line [24,25]. The most adverse network operating conditions were determined by a preliminary testing of the model, which consisted of changing the values of the admittance parameters of connections between the selected transmission line nodes. The results made it possible to limit the external network model to a model containing only connections between the individual voltage levels at the beginning and ending nodes of the line (Figure 9), for which this effect was obtained. The parameters estimated using this simplified equivalent system were the indicators used to differentiate the performed analyses. In each case, we compared the voltages and currents in the system when the transmission line was symmetric and asymmetric. The line length was the main parameter of our analysis, which was performed for Lines 2 and 3 (Table 2).

\subsection{Factors of Appearing Asymmetry with Symmetrical Supply and Load}

The preliminary analysis of the influence that elements creating connections between individual circuits on the appearing voltage asymmetry showed is that the worst operating conditions of the system occur when the circuits are electrically far apart from each other. These conditions occur when there are vanishingly small (i.e., close to zero) admittances of connections at both ends of the line, which can be simulated by opening all switchers S1-S6 (Figure 9). Thus, further calculations were carried out for such parametrization. The calculations consisted of determining the voltages and currents at the ends of individual circuits, the symmetrical components of these quantities, factor $\alpha_{0}$ (the zero-sequence voltage module ratio to its positive-sequence), and factor $\alpha_{2}$ (the negative-sequence voltage module ratio to its positive-sequence). The factors for currents were defined analogously. Due to the symmetry of the loads, they are numerically identical to the corresponding voltage factors.

For Line 3 (the line with greater geometric asymmetry), calculations were made for four cases: a load of Circuit I (400 kV) and Circuit II $(110 \mathrm{kV})$, a load of Circuit I and Circuit III $(110 \mathrm{kV})$, a load of all circuits carrying the maximum long-term permissible currents, and half of these currents. For the $400 \mathrm{kV}$ circuit, the long-term permissible current was $2850 \mathrm{~A}$, and for the $110 \mathrm{kV}$ circuits, $730 \mathrm{~A}$. The purpose of considering the first two cases was to determine which of the $110 \mathrm{kV}$ lines is more exposed to voltage asymmetry. The results presented in Figure 10 clearly confirm that the lower line (Circuit III) is more exposed to voltage asymmetry. In both these cases (the load on Circuits I and II, and Circuits I and III), the highest asymmetry factors appear in Circuit III. National regulations, according to [26], give only limit values of the $\alpha_{2}$ factor, which should not exceed $2 \%$. In the analysis of the diagram given in Figure 10b, it should be stated that this limit value is achieved for a 
line with a length of about $25 \mathrm{~km}$ with a full load of Circuits I and III and the open-circuit operation of Circuit II. Additionally, it should be noted that the values of $\alpha_{0}$ factors are relatively high, reaching several percentage points already at such lengths. This will result in high zero-sequence currents that may adversely impact the earth-fault protection and safe operation of the system.

(a)

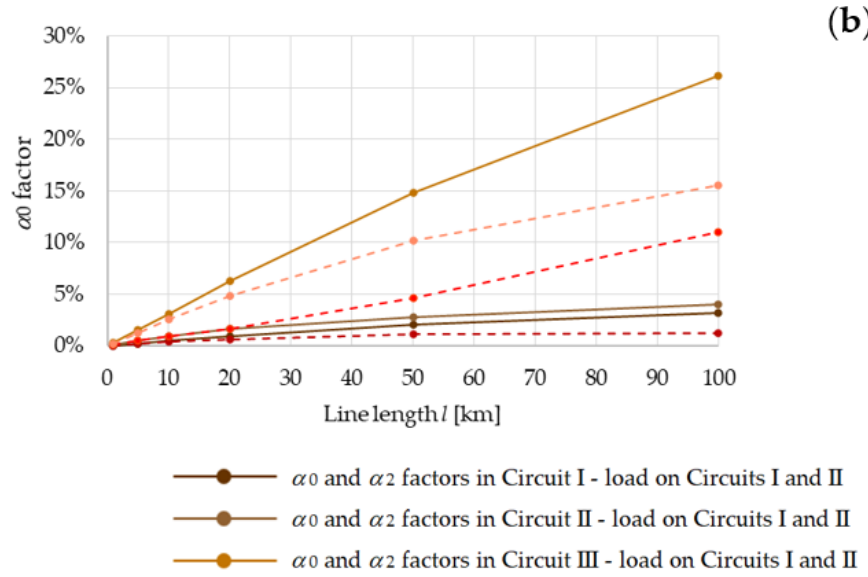

(b)

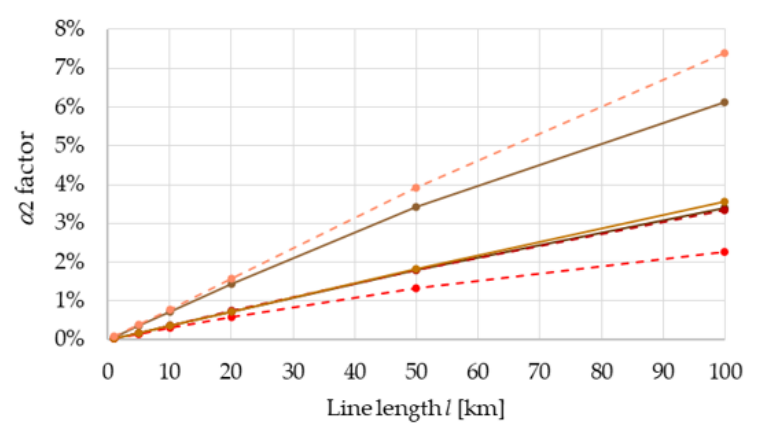

$---\alpha_{0}$ and $\alpha_{2}$ factors in Circuit I - load on Circuits I and III
$--\alpha_{0}$ and $\alpha_{2}$ factors in Circuit II - load on Circuits I and III
--
$---\alpha_{0}$ and $\alpha_{2}$ factors in Circuit III - load on Circuits I and III

Figure 10. Results of the analysis: (a) the $\alpha_{0}$ and (b) $\alpha_{2}$ factors for Line 3 with the load on two of the three circuits of the full long-term permissible current $I_{p}$.

Figure 11 shows the $\alpha_{0}$ and $\alpha_{2}$ factors for all circuits' load with the full and half values of the long-term permissible currents. The circuits' loading with half of the maximum long-term permissible currents is closer to the actual loads occurring in the power system's operation. In this case, the $\alpha_{2}$ factor reaches the limit at $30 \mathrm{~km}$ of the line length for the full load and $60 \mathrm{~km}$ for the reduced load (Figure 11b). However, even with a reduced load, the $\alpha_{0}$ factor values reach $5 \%$ and $8 \%$, respectively (Figure 11a). Much lower values are achieved by the factors for Circuit I with a $400 \mathrm{kV}$ voltage. These results confirm the necessity to perform transpositions on such lines. In this case, due to the relatively small distances between the phases of Circuits II and III $(110 \mathrm{kV})$, it is technically possible to transpose these circuits, e.g., using a triangular conductor configuration on transposition towers.

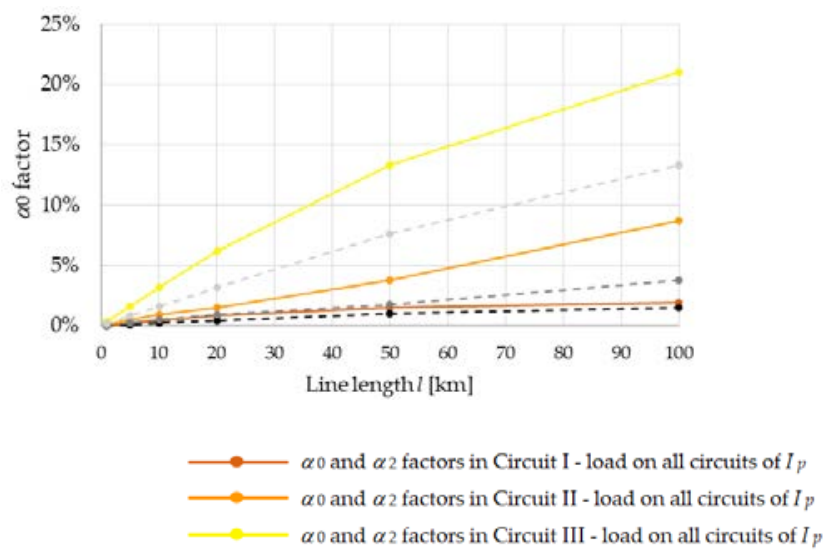

(a)

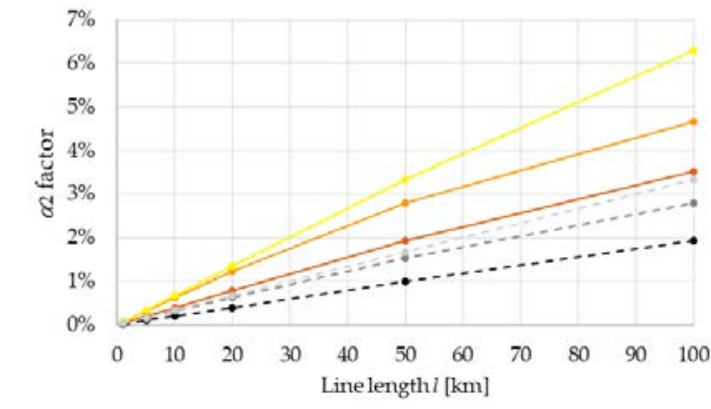

$---\alpha 0$ and $\alpha 2$ factors in Circuit I - load on all circuits of $0.5 I_{p}$

$---\alpha_{0}$ and $\alpha_{2}$ factors in Circuit II - load on all circuits of $0.51 p$ $\alpha 0$ and $\alpha_{2}$ factors in Circuit III - load on all circuits of $0.5 I p$

(b)

Figure 11. Results of the analysis: (a) the $\alpha_{0}$ and (b) $\alpha_{2}$ factors for Line 3 with the load on all line circuits of the full and half long-term permissible current $I_{p}$.

Due to the smaller geometric asymmetry and the estimated zero-sequence voltage results presented in Section 4 of the article, analyses were performed for Line 2, assuming a load of all circuits with their full and half maximum long-term permissible currents. For 
Circuits I and II (400 kV), the long-term permissible current was assumed as for Line 3, while for Circuit III ( $220 \mathrm{kV}$ ), the current was $1220 \mathrm{~A}$. Figure 12 shows the $\alpha_{0}$ and $\alpha_{2}$ factors in function of the line length.

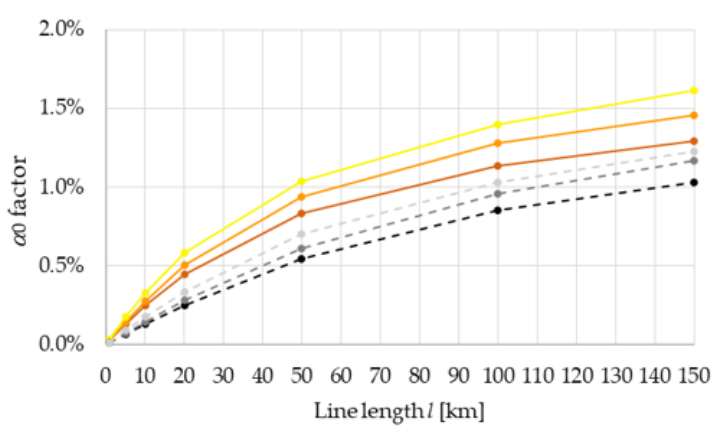

$\longrightarrow \quad \alpha_{0}$ and $\alpha_{2}$ factors in Circuit I - load on all circuits of $I p$
$\alpha 0$ and $\alpha_{2}$ factors in Circuit II - load on all circuits of $I p$
$\alpha 0$ and $\alpha_{2}$ factors in Circuit III - load on all circuits of $I p$

(a)

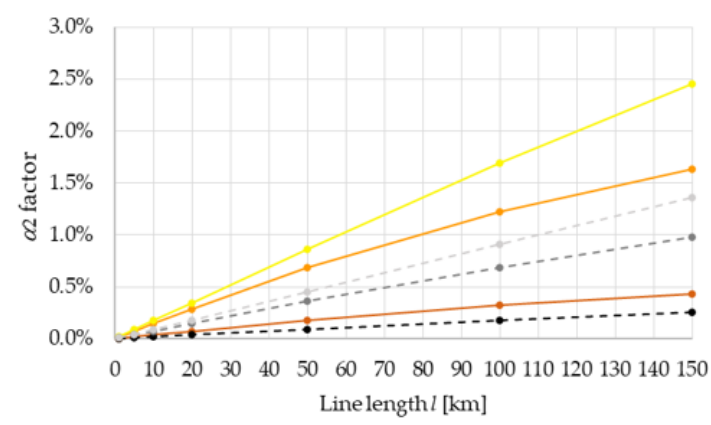

$--\bullet--\alpha_{0}$ and $\alpha_{2}$ factors in Circuit I - load on all circuits of $0.5 I p$ $---\alpha 0$ and $\alpha_{2}$ factors in Circuit II - load on all circuits of $0.5 I p$ $\alpha 0$ and $\alpha 2$ factors in Circuit III - load on all circuits of $0.5 I p$

(b)

Figure 12. Results of the analysis: (a) the $\alpha_{0}$ and (b) $\alpha_{2}$ factors for Line 2 with the load on all line circuits of the full and half long-term permissible current $I_{p}$.

For the analysis of Line 2, no significant values of both $\alpha_{0}$ and $\alpha_{2}$ factors were observed. Even for a $120 \mathrm{~km}$ long line, the limit value of these factors is not reached.

\subsection{Quantitative Comparison of Short-Circuit Currents for Symmetrical and Asymmetrical Models}

Using the system's model developed in this work, an analysis of the influence of the line asymmetry on short-circuit currents was also performed. In this case, three-phase and single-phase-to-earth faults at the end of Circuit III were modeled, as shown in Figure 9. As in the asymmetry analysis, for short-circuit studies, the systems for which the differences between the symmetric and asymmetric models are the greatest were determined. In this case, these are systems in which the ends of the individual circuit are electrically close to each other, which were realized by connecting a transformer between the ends of circuits with different voltages and couplings between circuits with the same voltage; such operation of circuits is reffered to as "close". Three system configurations described in Table 5 were analyzed, where the "close" operation of analyzed circuits was simulated by closing the corresponding switchers S1-S6 (Figure 9). For example, in the case where Circuits II and III are electrically "close" to each other, the switcher S6 is closed (Table 5). In such cases, short-circuit current components, i.e., high-value currents, flow through all circuits, and their interaction with each other is noticeable. Here, the analysis parameter was also the short-circuit power of the power supply systems. The basic values of shortcircuit power were adopted for 400,220 , and $110 \mathrm{kV}$, respectively: $S_{\mathrm{Q} 400}=27.7 \mathrm{GV} \cdot \mathrm{A}$, $S_{\mathrm{Q} 220}=15.2 \mathrm{GV} \cdot \mathrm{A}, S_{\mathrm{Q} 110}=7.6 \mathrm{GV} \cdot \mathrm{A}$. With an asymmetric model, the currents of singlephase-to-earth faults at a given location are different for each phase. For three-phase faults, the same currents do not flow in individual phases. 
Table 5. The short-circuit current changes indexes for Line 3 depending on the individual lines' connection system's ends.

\begin{tabular}{|c|c|c|c|c|c|}
\hline \multirow{2}{*}{ Case Studied } & \multirow{2}{*}{ Line Length } & \multicolumn{2}{|c|}{$\begin{array}{l}\text { Relative Circuit III Current Index in } \\
\text { Point B (Figure 9) during Fault }\end{array}$} & \multicolumn{2}{|c|}{$\begin{array}{l}\text { Relative Short-Circuit Current } \\
\text { Index in Point F (Figure 9) }\end{array}$} \\
\hline & & Three-Phase Fault & $\begin{array}{l}\text { Single-Phase- } \\
\text { to-Earth Fault }\end{array}$ & Three-Phase Fault & $\begin{array}{l}\text { Single-Phase- } \\
\text { to-Earth Fault }\end{array}$ \\
\hline & km & $\%$ & $\%$ & $\%$ & $\%$ \\
\hline Circuits I and III are "close" and & 10 & 6.02 & 3.91 & 2.23 & 2.72 \\
\hline Circuits II and III are "close" & 100 & 12.41 & 13.71 & 2.17 & 2.58 \\
\hline \multirow{2}{*}{ Circuits I and III are "close" } & 10 & 3.51 & 1.07 & 2.00 & 0.92 \\
\hline & 100 & 4.17 & 2.33 & 1.86 & 1.41 \\
\hline \multirow{2}{*}{ Circuits II and III are "close" } & 10 & 5.37 & 2.25 & 3.43 & 3.65 \\
\hline & 100 & 8.16 & 2.53 & 5.07 & 4.64 \\
\hline
\end{tabular}

For comparative purposes, the change of the short-circuit current index $I_{\%}$ was determined:

$$
I_{\%}=\frac{I_{\mathrm{as}}-I_{\mathrm{s}}}{I_{\mathrm{s}}} \cdot 100 \%
$$

where $I_{\mathrm{as}}$ is the maximum value of the phase current (for a single-phase-to-earth fault, $I_{\mathrm{as}}$ is the phase short-circuit current giving the highest value; for a three-phase fault, $I_{\mathrm{as}}$ is the highest current in the phase) at the fault location or in the tested line circuit for asymmetrical line model; and $I_{\mathrm{s}}$ is the phase current value at the fault location or in the tested line circuit for symmetrical line model.

Table 5 shows the values of the current change indexes for two line lengths $(10 \mathrm{~km}$ and $100 \mathrm{~km}$ ) with various arrangements of Line 3's ends operation for the basic values of the short-circuit power sources connected to the beginning of each line circuits.

The differences in the short-circuit currents are relatively small, reaching a maximum of about $5 \%$ for a $100 \mathrm{~km}$ line. More considerable differences were observed in the shares of these currents flowing through Circuit III phases, which reach over $13 \%$ for the long line with a single-phase-to-earth fault.

Another analysis was carried out to determine the impact of short-circuit powers on the differences of short-circuit currents (Table 6). The practical conclusion from these considerations is that the percentage currents differences depend only slightly on the short-circuit power value, both in the short-circuit currents and in their branch shares.

Table 6. Indexes of changes in short-circuit currents for Line 3 depending on the short-circuit power of the sources supplying individual circuits $\left(S_{\mathrm{Qx}}=1\right.$ means the basic short-circuit power).

\begin{tabular}{|c|c|c|c|c|c|}
\hline \multirow{3}{*}{$\begin{array}{l}\text { Relative Short-Circuit } \\
\text { Powers of the Systems }\end{array}$} & \multirow{2}{*}{ Line Length } & \multicolumn{2}{|c|}{$\begin{array}{l}\text { Relative Circuit III Current Index in } \\
\text { Point B (Figure 9) during Fault }\end{array}$} & \multicolumn{2}{|c|}{$\begin{array}{c}\text { Relative Short-Circuit Current Index in } \\
\text { Point F (Figure 9) }\end{array}$} \\
\hline & & Three-Phase Fault & $\begin{array}{l}\text { Single-Phase- } \\
\text { to-Earth Fault }\end{array}$ & Three-Phase Fault & $\begin{array}{l}\text { Single-Phase- } \\
\text { to-Earth Fault }\end{array}$ \\
\hline & km & $\%$ & $\%$ & $\%$ & $\%$ \\
\hline$S_{\mathrm{Q} 400}=1$ & 10 & 6.02 & 3.91 & 2.23 & 2.72 \\
\hline$S_{\mathrm{Q} 110}=1$ & 100 & 12.41 & 13.71 & 2.17 & 2.58 \\
\hline$S_{\mathrm{Q} 400}=1$ & 10 & 5.47 & 3.56 & 1.50 & 2.33 \\
\hline$S_{\mathrm{Q} 110}=0.5$ & 100 & 12.28 & 13.57 & 2.09 & 2.57 \\
\hline$S_{\mathrm{Q} 400}=0.5$ & 10 & 5.99 & 3.83 & 2.28 & 2.75 \\
\hline$S_{\mathrm{Q} 110}=1$ & 100 & 12.24 & 13.28 & 2.15 & 2.56 \\
\hline$S_{\mathrm{Q} 400}=0.5$ & 10 & 5.43 & 3.49 & 1.54 & 2.36 \\
\hline$S_{\mathrm{Q} 110}=0.5$ & 100 & 12.11 & 13.14 & 2.06 & 2.55 \\
\hline
\end{tabular}

Figure 13 shows the branch's current indexes' dependence for Line 2 and Line 3 (in Circuit III) in the function of the line length for a single-phase-to-earth and three-phase 
faults in the most unfavorable system operation condition, i.e., in the system where Circuits I and II are "close" to Circuit II at their ends. In this case, a clear relation of the index I\% with the line length was observed. For three-phase faults, the indexes' values begin to stabilize and level off with increasing length, while the single-phase-to-earth faults curves continue to increase.

(a)

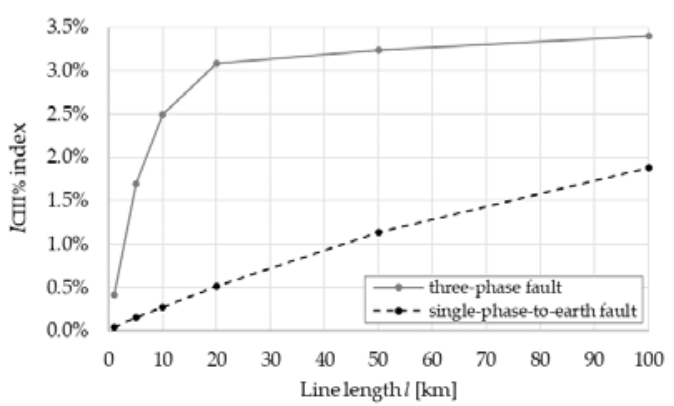

(b)

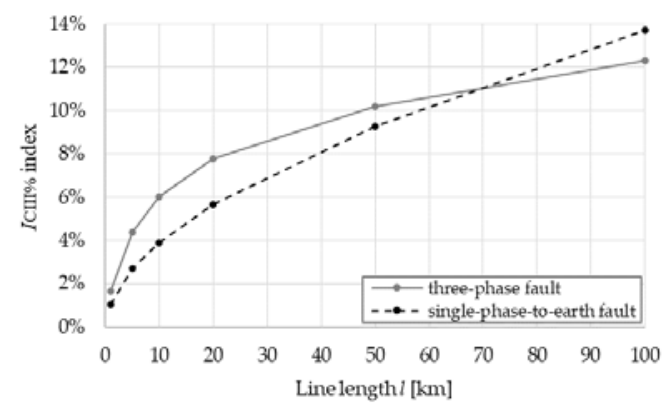

Figure 13. Relative Circuit III current indexes in the function of line length $l$ for (a) Line 2 and (b) Line 3.

\section{Summary and Conclusions}

The increased demands for electrical energy, the development of a generation of unstable energy production, and continuous efforts to improve power supply reliability make it necessary to expand the transmission system. On the other hand, environmental constraints make it challenging to build and operate new transmission lines. A certain compromise between these opposing interests is the construction of multi-circuit lines, especially multi-voltage ones. In terms of the occupied area's width for the construction of overhead lines and the electromagnetic field strength in the line's vicinity, this solution is very beneficial, which we have shown in Sections 1 and 3. However, there are also new problems in the design and modeling of such elements. The article focused on two issues, i.e., line design from the mechanical (i.e., selection of the optimal span length) and electrical (i.e., an analysis of the effect asymmetry has on the electrical parameters of the line, namely, the impedance and capacitance) point of view. The asymmetry of transmission line electrical parameters affects the operation of the entire line electrical environment and the accurate determination of the characteristic short-circuit currents associated with the selection of conductors, as well as the operation of the transmission line protection automatics.

The analysis we performed shows that, from the mechanical point of view, for shared transmission line construction with different voltage ratings, primarily when a $110 \mathrm{kV}$ circuit is carried with 400 and/or $220 \mathrm{kV}$ lines, there may be some difficulties with the coordination of stresses and sags, but a compromise is possible in this case. The problem practically does not occur when all circuits are made of similar conductor types (as in the 400 and $220 \mathrm{kV}$ lines).

In terms of the phases of its individual circuits, a multi-circuit line is an asymmetric element that can be symmetrized by the conductor transposition of the individual line circuits. However, this is a complicated procedure to implement, in which it would sometimes be necessary to place an additional tower next to the main path of the line. The asymmetrical structure results in the asymmetry of the electrical parameters of the line. Analyzing the transmission line impedances and capacitances separately, we focused on showing the effect of the zero-sequence voltage appearing in the unsupplied circuit under the influence of symmetrical voltage in other circuits (capacitance asymmetry, as seen in Figure 8) and the influence of the zero-sequence voltage appearing in the supplied but unloaded circuit under the influence of symmetrical loading of other circuits (impedance asymmetry, as seen in Figures $5 \mathrm{~b}$ and $6 \mathrm{~b}$ ). The influence of the zero-sequence voltage is especially visible in the circuits with the lowest rated voltage. It is different for various 
line geometries, and hence a conclusion on the certain possibilities of optimizing the circuits' position in relation to each other was derived.

The second computational aspect of the article was the estimation of the voltage quality factors $\alpha_{0}$ and $\alpha_{2}$ that may appear during the operation of the asymmetrical multi-circuit lines in the power system, as well as errors in the estimates of short-circuit currents when using a symmetrical model instead of an exact asymmetrical one. The analyses carried out on two types of three-circuit lines with small (Line 2) and large (Line 3) geometric asymmetry show that for Line 3, both the asymmetry factors and the current indexes, even for short sections of such lines (several kilometers), can be significant and can affect the correct operation of the entire system. The symmetrical model can be used for lines with small geometric asymmetry, even for relatively long lines (of several dozen kilometers). It follows that for specific objects, such as multi-circuit, multi-voltage lines, the electric models of these lines should be determined as exact, and only in exceptional cases can simplified symmetrical models be adopted. It is also necessary to use conductor transposition, especially in the case of carrying 400 and $110 \mathrm{kV}$ circuits on a shared structure [27], which is possible using appropriate towers.

Author Contributions: A.D., H.K., and P.K. contributed equally to this work and all of its stages and elements. All authors have read and agreed to the published version of the manuscript.

Funding: This research received no external funding.

Institutional Review Board Statement: Not applicable.

Informed Consent Statement: Not applicable.

Data Availability Statement: No new data were created or analyzed in this study. Data sharing is not applicable to this article.

Conflicts of Interest: The authors declare no conflict of interest.

\section{References}

1. Riba, J.-R.; Bogarra, S.; Gómez-Pau, Á.; Moreno-Eguilaz, M. Uprating of transmission lines by means of HTLS conductors for a sustainable growth: Challenges, opportunities, and research needs. Renew. Sustain. Energy Rev. 2020, 134. [CrossRef]

2. Drager, H.-J.; Hussels, D.; Puffer, R. Development and Implementation of a Monitoring-System to Increase the Capacity of Overhead Lines. CIGRE Session Papers \& Proceedings 2008; Paris, France, 2008; p. B2-101. Available online: https://e-cigre.org/ publication/SESSION2008-2008-cigre-session (accessed on 20 November 2020).

3. Song, F.; Wang, Y.; Zhao, L.; Qin, L.; Liang, L.; Yin, Z.; Tao, W. Study on Thermal Load Capacity of Transmission Line Based on IEEE Standard. J. Inf. Process. Syst. 2019, 15, 464-477. [CrossRef]

4. Standard PN-EN 50341-2-22:2016-04 Overhead Electrical Lines Exceeding AC 1 kV-Part 2-22: National Normative Aspects (NNA) for Poland (based on EN 50341-1:2012). 2016. Available online: https://standards.iteh.ai/catalog/standards/clc/f88050 ec-0acb-4984-8334-c6efb6cdc03f/en-50341-2-22-2016 (accessed on 30 November 2020).

5. NationalGrid newsletter note: Hinkley Connection Project Begins 12-Month Countdown to Construction of UK's First Operational T-Pylons. Available online: www.nationalgrid.com (accessed on 20 November 2020).

6. Tennet Newsletter Note: The Wintrack Pylon-An Innovative Solution for New High-Voltage Lines; Information. Available online: www.tennet.eu (accessed on 20 November 2020).

7. Kumala, R. Identification of disturbances in multi-circuit, different level voltage power lines. In Dissertation; Silesian University of Technology: Gliwice, Poland, 2016. (In Polish)

8. Development Plan for Meeting the Current and Future Electricity Demand for the Years 2018-2027. 2019. Available online: https://www.pse.pl/web/pse-eng/documents (accessed on 20 November 2020).

9. Douglass, D.; Gaudry, M.; Hoffmann, S. Sag-tension calculation methods for overhead lines. In CIGRE Technical Brochure No. 324; Task Force B2.12.3; CIGRE: Paris, France, 2016.

10. Pang, X.-F.; Liu, L. Variations of Proliferation States of Cells Under Action of Electromagnetic Field of High-Voltage Transmission Lines. In Proceedings of the 2007 IEEE/ICME International Conference on Complex Medical Engineering, Beijing, China, 23-27 May 2007. [CrossRef]

11. Das, H.; Gogi, K.; Chatterjee, S. Analysis of the effect of electric field due to High Voltage Transmission lines on humans. In Proceedings of the 2015 1st Conference on Power, Dielectric and Energy Management at NERIST (ICPDEN), Itanagar, India, 10-11 January 2015. [CrossRef]

12. IRPA/INIRC. Interim guidelines on limits of exposure to $50 / 60 \mathrm{~Hz}$ electric and magnetic fields. Health Phys. 1990, 58, 113-122.

13. ICNIRP. Guidelines for limiting exposure to time-varying electric, magnetic and electromagnetic fields. Health Phys. 1998, 74, 4 . 
14. Journal of Laws of 2003 No. 192, Item 1883: Regulation of the Minister of the Environment of 30 October 2003 on the Permissible Levels of Electromagnetic Fields in the Environment and Methods of Checking Compliance with These Levels. Available online: https: / / www.prawo.egospodarka.pl/akty/dziennik-ustaw/2003/192/1883 (accessed on 20 November 2020). (In Polish).

15. Standard PN-EN 50341-1:2013-03: Overhead Electrical Lines Exceeding ac $1 \mathrm{kV}$-Part 1: General Requirements. Common Specifications. Available online: https:/ /standards.iteh.ai/catalog/standards/clc/618d1923-c8f0-4c7b-9a5a-ba47a4c37551/en50341-1-2012 (accessed on 30 November 2020).

16. Mujezinović, A.; Čarsimamović, S.; Čarsimamović, A.; Muharemović, A.; Turković, I. Electric field calculation of overhead transmission lines in Bosnia and Herzegovina. In Proceedings of the 2014 International Symposium on Electromagnetic Compatibility, Gothenburg, Sweden, 1-4 September 2014. [CrossRef]

17. Deltuva, R.; Lukočius, R. Distribution of Magnetic Field in 400 kV Double-Circuit Transmission Lines. 2020. Appl. Sci. 2020, 10, 3266. [CrossRef]

18. Clarke, E. Circuit Analysis of A-C Power Systems; J. Wiley \& Sons Inc.: New York, NY, USA, 1943; Volume 1.

19. Dommel, H.W. Electro-Magnetic Transients Program (EMTP) Theory Book, 2nd ed.; Microtran Power System Analysis Corporation: Portland, Oregon, 1996.

20. Carson, J.R. Wave Propagation in Overhead Wires with Ground Return. Bell Syst. Tech. J. 1926, 5, 539-554. [CrossRef]

21. Kocot, H.; Dziendziel, A. Impedance models of multi-circuit multi-voltage overhead lines. Prz. Elektrotech. 2019, 7, 257-260. [CrossRef]

22. Tarko, R.; Szpyra, W.; Nowak, W. Analysis of Possibilities to Reduce the Voltages Inducted in Multi-circuit and Multi-voltage Overhead Lines. Acta Energetica 2015, 3, 130-136. [CrossRef]

23. Kocot, H.; Dziendziel, A. Chosen analyses for multi-circuit multi-voltage overhead lines capacitances. Prz. Elektrotech. 2020, 96, 71-74. [CrossRef]

24. Ward, J.B. Equivalent Circuits for Power Flow Studies. Trans. Am. Inst. Electr. Eng. 1949, 68, 373-382. [CrossRef]

25. Milano, M.; Srivastava, K. Dynamic REI equivalents for short circuit and transient stability analyses. Electr. Power Syst. Res. 2009, 79, 878-887. [CrossRef]

26. Journal of Laws of 2007 No. 93, Item 623: Regulation of the Minister of Economy of 4 May 2007 on the Detailed Conditions for the Operation of the Power System. Available online: prawo.sejm.gov.pl/isap.nsf/DocDetails.xsp?id=WDU20070930623 (accessed on 20 November 2020). (In Polish)

27. Novitskiy, A.; Westermann, D. Interaction of Multi-Circuit Overhead Transmission Lines of Different Voltages Located on the Same Pylons. In Proceedings of the 2012 Electric Power Quality and Supply Reliability, Tartu, Estonia, 11-13 June 2012; pp. 1-4. [CrossRef] 